\title{
Mapeamento de cianobactérias por meio da fluorescência da ficocianina e de análise geoestatística
}

\author{
Alex G. Utsumi ${ }^{1}$, Maria de L. B. T. Galo ${ }^{2}$ \& Vilma M. Tachibana ${ }^{3}$
}

\section{Palavras-chave:}

fluorescência in vivo

grupos fitoplanctônicos

krigagem ordinária

\begin{abstract}
R E S U M O
O florescimento de cianobactérias em águas continentais é um problema mundial que deve ser monitorado pelo potencial risco que representa à saúde humana. $\mathrm{O}$ objetivo deste estudo foi mapear a ocorrência de cianobactérias por meio da integração de medidas de fluorescência in vivo do pigmento ficocianina e da análise geoestatística. Os dados fluorimétricos foram coletados em 59 pontos de amostragem georreferenciados no reservatório de Nova Avanhandava, São Paulo, em dezembro de 2011. Analisaramse, para caracterização do ambiente aquático, parâmetros limnológicos da água além da identificação dos grupos fitoplanctônicos constatando-se a presença de gêneros tóxicos de cianobactérias. Os valores de concentração de ficocianina variaram entre 1 a $10 \mu \mathrm{g} \mathrm{L}^{-1}$, sinalizando o potencial do método em detectar cianobactérias, mesmo em estágio inicial de florescimento. A análise geoestatística permitiu detectar a anisotropia dos dados de concentração de ficocianina, de modo que o modelo esférico se ajustou melhor para realizar a krigagem ordinária. A validação do modelo resultou em um erro médio quadrático de 0,98 , além de permitir modelar a incerteza associada à inferência.
\end{abstract}

\section{Key words:}

in vivo fluorescence phytoplankton groups ordinary kriging

\section{Mapping of cyanobacteria using phycocyanin fluorescence and geostatistical analysis}

\begin{abstract}
A B S T R A C T
Bloom of cyanobacteria in continental waters is a worldwide problem that should be monitored by the potential risk posed to human health. This study aimed to map the occurrence of cyanobacteria through integration of fluorimetric in vivo phycocyanin pigment method and geostatistical analysis. Fluorimetric data were collected from 59 georeferenced sampling points in New Avanhandava reservoir, São Paulo, in December 2011. In order to characterize aquatic environment, limnological parameters were analysed. Besides, phytoplankton groups identification were performed, noting the presence of toxic cyanobacterial genera. Values of phycocyanin concentration ranged between 1 to $10 \mu \mathrm{g} \mathrm{L}^{-1}$, indicating the potential of the method for cyanobacteria detection, even in early stages of bloom. Geostatistical analysis allowed detecting phycocyanin concentration anisotropy, which adjusted better in spherical model to perform ordinary kriging. Model validation resulted in Root Mean Square equal to 0.98, besides allows modeling the inference uncertainty.
\end{abstract}




\section{INTRODUÇÃo}

Dentre os diversos grupos que formam o fitoplâncton as cianobactérias são consideradas o mais problemático do ponto de vista sanitário, pela existência de algumas espécies potencialmente tóxicas. Em diversos países é crescente a preocupação em referência à floração de cianobactérias e aos danos à saúde humana por ingestão de água contaminada ou outro tipo de contato com esses micro-organimos já foram reportados na Austrália, Reino Unido, China e África do Sul.

O Brasil possui um histórico em relação à contaminação humana por cianobactérias em que o caso mais grave foi a chamada "Síndrome de Caruaru", em 1996, quando 130 pacientes renais crônicos passaram a apresentar um quadro clínico compatível com uma grave hepatotoxicose, após sessões de hemodiálise em uma clínica da cidade de Caruaru (PE), culminando com o falecimento de 60 pacientes após o início dos sintomas. Análises posteriores confirmaram a presença de microcistinas e cilindrospermopsina no carvão ativado utilizado no sistema de purificação de água da clínica e de microcistinas em amostras de sangue e fígado dos pacientes intoxicados (FUNASA, 2003).

Atualmente, o monitoramento de cianobactérias é feito por métodos limnológicos tradicionais de laboratório que envolve a identificação de espécies potencialmente tóxicas e o acompanhamento de suas densidades, por meio de contagem. Esses métodos nem sempre são eficientes pelo fato das resoluções temporal e espacial de amostragem convencional não permitirem a detecção em mudanças na biomassa do fitoplâncton, sobretudo durante condições de florescimento (Calijuri et al., 2006; Agha et al., 2012).

Nesta vertente, pesquisadores têm trabalhado em busca de soluções mais adequadas para monitoramento da qualidade da água, que sejam capazes de conciliar baixo custo com a alta efetividade na coleta da informação. Uma das abordagens é o estudo das propriedades ópticas do fitoplâncton para obtenção de informações qualitativas e quantitativas desses organismos. As cianobactérias têm, em sua estrutura, um pigmento fitoplanctônico singular, denominado ficocianina, que possui propriedades ópticas peculiares, inclusive fluorescentes (Seppala et al., 2007; Agha et al., 2012). Essas propriedades fluorescentes ainda são objeto de várias pesquisas mas consideram o fato de que diferente das algas eucarióticas, que são excitadas pela luz azul e definem um pico de emissão próximo a $685 \mathrm{~nm}$, as cianobactérias possuem excitação nas regiões laranja e vermelha do espectro, com pico de emissão em torno de $650 \mathrm{~nm}$ (Gregor et al., 2007).

Recorre-se, usualmente, à análise laboratorial para a estimativa da biomassa fitoplanctônica a partir das propriedades fluorescentes de seus pigmentos. Esta abordagem exige a utilização da tecnologia in vitro, da qual é necessária a extração química do pigmento sem que haja deterioração do fitoplâncton. O desenvolvimento de instrumentos de campo que utilizam o princípio da fluorescência in vivo, no qual a fluorescência é percebida externamente ao organismo, tem tornado operacional e otimizado o monitoramento de cianobactérias no corpo aquático. Além disso, a mensuração realizado em campo possibilita coletar um número maior de elementos amostrais, tanto quanto a obtenção de dados em fluxo contínuo.
A técnica da fluorescência in vivo mostra-se eficiente, mesmo em baixas concentrações ou com amplitude de variação reduzida (Seppala et al., 2007; Song et al., 2013) e permite, para elementos amostrais georreferenciados, realizar a inferência espacial da concentração de ficocianina em áreas não amostradas e identificar locais mais críticos quanto à ocorrência de cianobactérias.

A possibilidade de tratar adequadamente fenômenos ambientais que têm a propriedade de variar em diferentes direções no espaço, indica o potencial da geoestatística no mapeamento do fitoplâncton. Segundo Landim (1998), a geoestatística é um ramo da estatística que trata de problemas associados a variáveis regionalizadas, as quais possuem características tanto verdadeiramente casuais quanto totalmente determinísticas. Tais variáveis possuem a tendência de apresentar valores muito similares em dois pontos vizinhos e, à medida em que os pontos começam a se distanciar, os valores estimados se tornam cada vez mais distintos. A geoestatística permite a estimativa de valores em locais não amostrados de modo que não haja tendência com um erro mínimo.

Neste contexto objetivou-se mapear a ocorrência de cianobactérias em uma área no reservatório de Nova Avanhandava, localizado no médio curso do rio Tietê, estado de São Paulo, a partir da integração de medidas fluorimétricas in vivo do pigmento fotossintetizante ficocianina e análise geoestatística. Espera-se, então, que os métodos propostos e os mapas gerados possam fornecer subsídios visando estabelecer um programa de monitoramento que se constitua efetivamente em um sistema de alerta para florescimento de cianobactérias.

\section{Material e Métodos}

A metodologia adotada iniciou-se com a utilização de imagens multiespectrais a fim de definir uma área com ocorrência de fitoplâncton, no contexto do Reservatório de Nova Avanhandava. Utilizou-se, além das imagens, um sensor fluorimétrico capaz de registrar concentrações do pigmento ficocianina de modo que as atividades fossem desenvolvidas em dois níveis de detalhamento; em um primeiro momento realizou-se uma missão de campo exploratória culminando com a definição da área estudos e da época de maior ocorrência de fitoplâncton no sítio selecionado enquanto o segundo momento constitui da aquisição de medidas fluorimétricas georreferenciadas na área selecionada de acordo com o delineamento amostras específicas para a realização do presente estudo.

O Reservatório de Nova Avanhandava, localizado na Bacia do Baixo Rio Tietê, se estende por uma área de 210 $\mathrm{km}^{2}$ e se caracteriza por apresentar usos múltiplos, tais como: abastecimento público e industrial, irrigação, navegação e despejo de efluentes. Em um levantamento exploratório de campo, realizado em fevereiro de 2011, observou-se atividade fitoplanctônica intensa em locais específicos do reservatório, o que levou à definição de uma área de aproximadamente 17 ha para desenvolver o estudo. A Figura 1 mostra um detalhamento da área de estudos demarcada por um retângulo em vermelho, sobre uma imagem multiespectral obtida pelo sistema orbital RapidEye; enquanto que a delimitação dessa área no contexto 

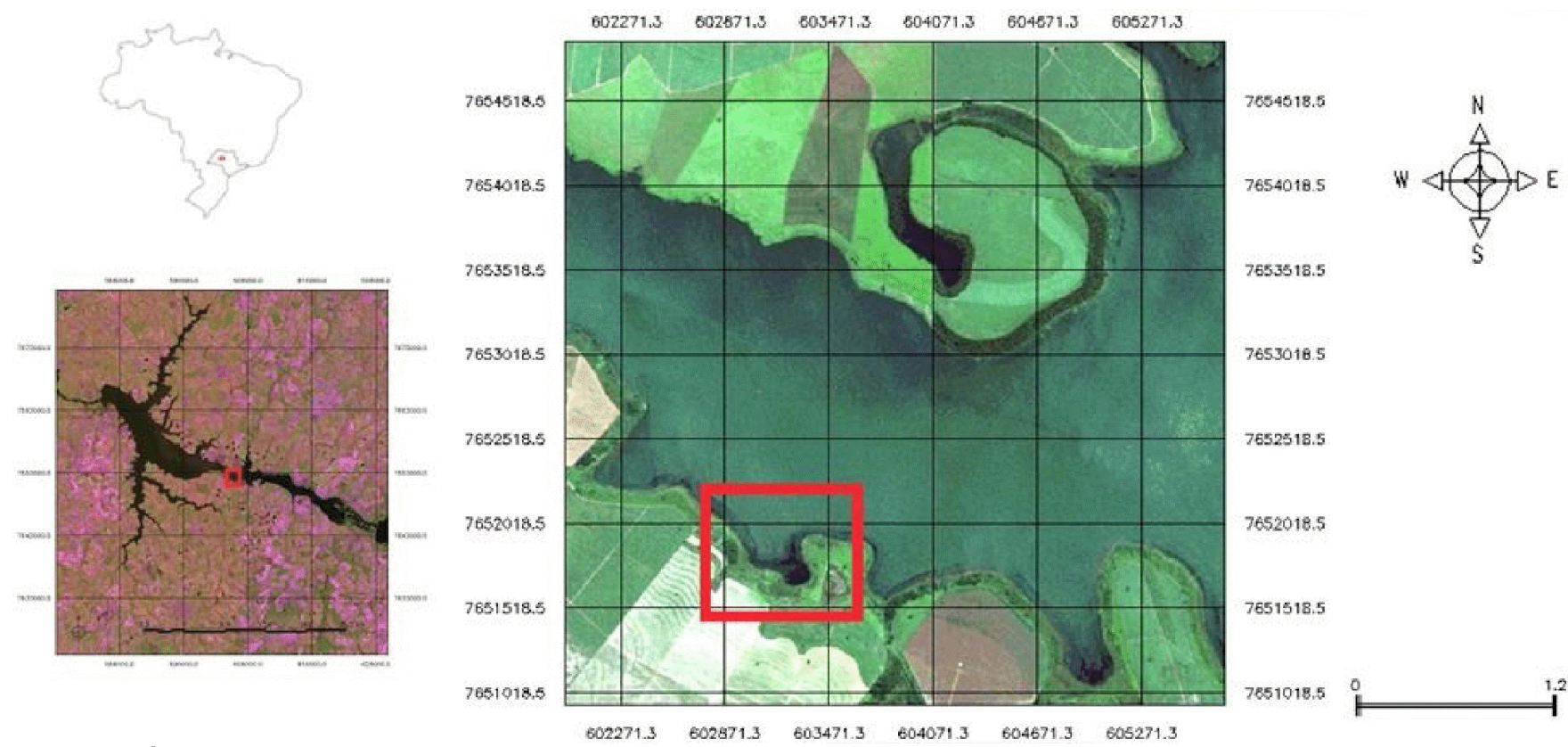

7653016.5

7652518.5

$\$ 2018.5$

51518.5

7851018.5

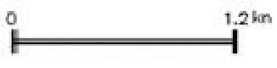

Figura 1. Área de estudos selecionada no reservatório de Nova Avanhandava

do Reservatório de Nova Avanhandava é feita em uma composição colorida (R5G4B3) de imagem multiespectral TM/Landsat-5.

A partir da análise visual de imagens multiespectrais TM/Landsat-5, do período entre outubro de 2008 e abril de 2011, foram observados dois grupos distintos associados a variações na intensidade de resposta espectral do corpo d'água. As maiores intensidades na cor da água ocorreram no período do verão, decorrente da maior concentração de sólidos suspensos, consequência do aumento das chuvas e do carreamento de sólidos para o corpo d'água. Considerando que o referido ambiente, rico em nutrientes e associado ao aumento da temperatura e da intensidade dos ventos, se torna propício para o florescimento do fitoplâncton, estabeleceu-se o período entre os meses de novembro a fevereiro para realizar a campanha de campo.

O tamanho da amostra para adquirir a variável concentração de ficocianina ficou definido em setenta elementos amostrais distribuídos por toda a área de estudos (de modo a otimizar a inferência por geoestatística) porém com um adensamento de pontos em locais em que se observou maior atividade fotossintética em levantamento exploratório anterior. A localização de cada um dos 70 pontos foi armazenada em um receptor GNNS Garmin, para posterior posicionamento dos pontos em campo.

As medidas de concentração de ficocianina foram tomadas por fluorômetro Unilux (Chelsea Techonologies@) que opera com a radiação emitida e excitada por fluorescência in vivo. $\mathrm{O}$ fluorômetro possui um sensor óptico com filtro de excitação para ficocianina em $610 \mathrm{~nm}$ e detecção no comprimento da onda em $685 \mathrm{~nm}$, o qual realiza as leituras em um intervalo de 0 a $100 \mu \mathrm{g} \mathrm{L}^{-1}$ e limite mínimo de detecção de $0,01 \mu \mathrm{g} \mathrm{L}^{-1}$. As medições foram feitas nos pontos previamente selecionados deslocando-se um barco até a coordenada do ponto armazenada no receptor GNNS e posicionando o fluorômetro Unilux a uma profundidade de $20 \mathrm{~cm}$ abaixo da superfície da água.

No processamento dos dados 11 leituras tiveram que ser excluídas por apresentarem variações inconsistentes nas concentrações de ficocianina, sobremaneira em locais próximos à ocorrência de macrófitas submersas ou regiões mais rasas, quando o aparelho estava a centímetros do fundo do reservatório. Os 59 elementos da amostra foram, então, divididos em conjunto de inferência constituído pelos 40 elementos amostrais utilizados na modelagem, e conjunto de validação, com os 19 pontos remanescentes. A Figura 2 apresenta a distribuição dos elementos amostrais na área de estudos discriminando aqueles que constituem a amostra de inferência (indicados em amarelo) e a de validação (azul).

Foi feita ainda, na campanha de campo, a coleta de água em 9 pontos amostrais, dentre os 59 anteriores, para caracterizar a ocorrência de clorofila-a, na área de estudo. As alíquotas coletadas foram armazenadas em recipientes opacos, acondicionados em caixa térmica com gelo e filtradas no final do dia, em ambiente escuro. A extração da clorofila-a foi realizada em laboratório adotando-se o procedimento de Goterman (1978).

Para uma caracterização geral do ambiente aquático em estudo foram medidas, em 7 pontos de aquisição de dados, as

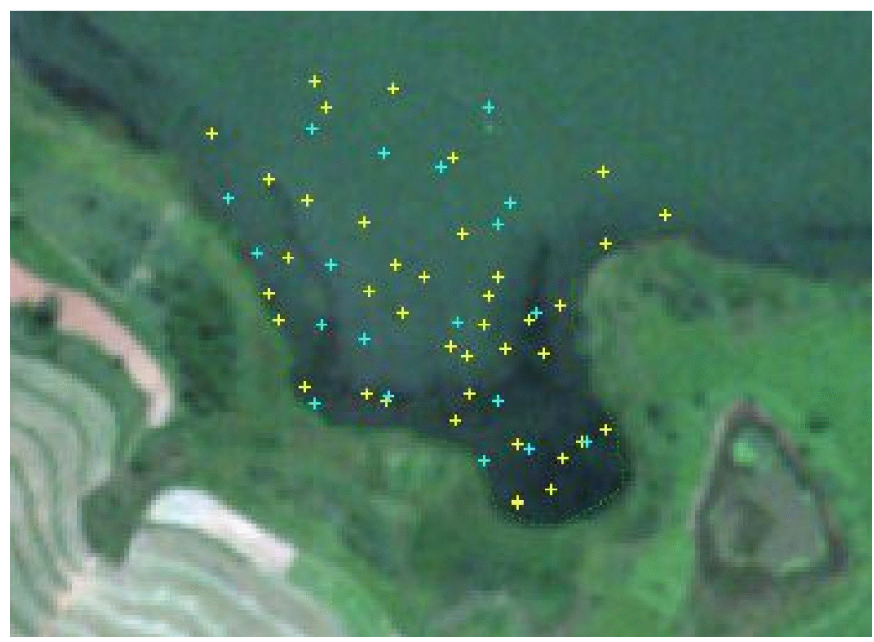

Figura 2. Distribuição das amostras divididas dentre aquelas utilizadas para a inferência (amarelo) e validação (azul) 
variáveis físicas turbidez, temperatura, oxigênio dissolvido, $\mathrm{pH}$, condutividade e profundidade do disco de Secchi. Também foram coletadas, neste levantamento, amostras de água para identificar os gêneros fitoplanctônicos presentes e a densidade da comunidade fitoplanctônica em dois elementos amostrais. Para tal, a amostra foi preservada com solução lugol e encaminhada para análise laboratorial (contagem).

A inferência espacial da concentração de ficocianina foi feita a partir dos 40 elementos da amostra de modelagem utilizando-se o software Idrisi, versão Andes. O aplicativo Spring foi utilizado para elaborar a representação temática dos intervalos de concentração de ficocianina.

Para realizar a inferência da ficocianina por meio da krigagem ordinária foi necessário avaliar o grau de dependência espacial entre os elementos da amostra; para isto, foram gerados os semivariogramas nas direções de $0^{\circ}, 45^{\circ}, 90^{\circ}$ e $135^{\circ}$, todos com abertura angular de $45^{\circ}$, e o omnidirecional. Os semivariogramas construídos para este estudo tiveram 10 espaçamentos com valor de comprimento de $40 \mathrm{~m}$, resultando em uma distância máxima de $400 \mathrm{~m}$.

Aplicado o modelo de inferência espacial, realizou-se um fatiamento dos valores interpolados de concentração de ficocianina em intervalos regulares de $2 \mu \mathrm{g} \mathrm{L} \mathrm{L}^{-1}$, gerandose o mapa temático final. Para avaliar a confiabilidade dos valores estimados considerando-se a amostra de validação, foi elaborado o mapa da variância do erro de estimação para a variável ficocianina. Visando validar o processo de inferência espacial das amostras, foi utilizado o erro médio quadrático (EMQ) apresentado na Eq. 1:

$$
\sigma^{2}=\sum \frac{\mathrm{e}^{2}}{\mathrm{n}}
$$

em que:

$$
\begin{array}{ll}
\sigma^{2} & \text { - erro médio quadrático } \\
\mathrm{e}^{2} & \text { - quadrado dos erros verdadeiros ou aparentes } \\
\mathrm{n} & \text { - número de amostras. }
\end{array}
$$

\section{Resultados e Discussão}

O levantamento de dados no Reservatório de Nova Avanhandava foi realizado nos dias 12 e 13 de dezembro de 2011, dentro do período do ano de maior atividade fitoplanctônica (novembro a fevereiro) definido pela análise visual das imagens e reconhecimento preliminar in situ. As mensurações e a coleta de água foram feitas em condições de céu limpo e sem precipitações de chuvas no período, com ventos com baixa velocidade definindo uma superfície aquática sem ondulações. A Tabela 1 apresenta os valores médios resultantes das medições das variáveis físicas, os quais refletem a condição homogênea da água da área de estudos.

A temperatura média da água foi de $30,2{ }^{\circ} \mathrm{C}$, com baixa turbidez. A variável profundidade do disco de Secchi foi de 2,64 $\mathrm{m}$ porém em alguns locais não foi possível sua aquisição uma vez que este se encontrava limitado pelo fundo do reservatório ou pela presença de plantas aquáticas. A concentração média de clorofila-a foi de $4,43 \mu \mathrm{g} \mathrm{L}^{-1}$, com variações entre 2,53 e 8,64 $\mu \mathrm{g} \mathrm{\textrm {L } ^ { - 1 }}$, indicando a característica de corpo d'água oligotrófico para esta variável, no período de aquisição das medidas.

A identificação dos grupos algais e a contagem de indivíduos indicaram a presença de diferentes grupos fitoplanctônicos em proporções distintas: Chlorophyceae (3,32\%), Cyanobacteria (67,05\%), Bacillariophyceae (6,88\%), Zygnemaphyceae (5,69\%), Crysophyceae (0,83\%), Euglenophyceae (1,78\%) e Cryptophyceae (14,47\%). A proporção de ocorrência indica a dominância do grupo de cianobactérias (Cyanobacteria); entretanto, a densidade total da comunidade fitoplanctônica (843 indivíduos $\mathrm{mL}^{-1}$ ) é, ainda, característico de um ambiente pouco impactado pelo fitoplâncton. Por outro lado, $94,5 \%$ dos gêneros de cianobactérias identificados na amostra são potencialmente tóxicos representados por $27,6 \%$ do gênero Microcystis, 40,2\% de Cylindrospermopsis, 20,2\% de Anabaena e 6,55\% de Pseudanabaena. Considerando-se a dominância de cianobactérias nas duas amostras coletadas e a quase exclusividade de gêneros com potencial para desenvolver toxidade, mesmo com pouca atividade fitoplanctônica na área, é importante considerar a área de estudos como um local a ser monitorado.

A concentração de ficocianina medida por fluorescência in vivo do pigmento, resultou em uma média de $3,76 \mu \mathrm{g} \mathrm{L}^{-1}$, entre o valor mínimo de $1,0 \mu \mathrm{g} \mathrm{\textrm {L } ^ { - 1 }}$ e máximo de $10,0 \mu \mathrm{g} \mathrm{\textrm {L } ^ { - 1 }}$. Na análise dos valores de concentração de ficocianina deve-se considerar as condições sazonais e do próprio ambiente que, neste caso, se trata de estágio inicial de florescimento do fitoplâncton. Analisando a diversidade de algas em 800 ambientes aquáticos, Brient et al. (2008), mostraram que em concentrações de ficocianina superiores a $10 \mu \mathrm{g} \mathrm{L}^{-1}$, as cianobactérias dominam o ambiente em densidades preocupantes.

O estudo realizado confirma o potencial de detecção de cianobactérias por meio da fluorescência in vivo, apontado por Bastien et al. (2011), Brient et al. (2008) e Izydorczyk et al. (2005), entre outros, e indica que esse tipo de abordagem pode constituir-se em um mecanismo eficiente de alerta de cianobactérias em estágio inicial de florescimento.

A inferência espacial da concentração de ficocianina por geoestatística partiu da análise do comportamento da distribuição da variável por meio dos semivariogramas definidos para as quatro direções $\left(0^{\circ}, 45^{\circ}, 90^{\circ}\right.$ e $\left.135^{\circ}\right)$, o que permitiu detectar a anisotropia dos dados. Este comportamento é observado na maioria das variáveis ambientais, sendo necessária a modelagem nas direções de maior $\left(135^{\circ}\right)$ e menor $\left(45^{\circ}\right)$ continuidade para se obter resultados mais satisfatórios (Figura 3).

\begin{tabular}{|c|c|c|c|c|c|c|}
\hline & $\begin{array}{c}\text { Temperatura } \\
\left({ }^{\circ} \mathrm{C}\right)\end{array}$ & $\begin{array}{c}\text { Disco } \\
\text { de Secchi (m) }\end{array}$ & $\begin{array}{c}\text { Turbidez } \\
\text { (NTU) }\end{array}$ & $\begin{array}{c}\text { Condutividade } \\
\left(\mu \mathrm{C} \mathrm{cm}^{-1}\right)\end{array}$ & $\begin{array}{c}\text { Oxigênio dissolvido } \\
\left(\mathrm{mg} \mathrm{L}^{-1}\right)\end{array}$ & pH \\
\hline Média & 30,2 & 2,64 & 10,84 & 140,9 & 8,5 & 5,76 \\
\hline Mínimo Valor & 29,5 & 2,2 & 9 & 139 & 7 & 5,2 \\
\hline Máximo Valor & 31,5 & 3 & 13,3 & 142,5 & 9,5 & 6,3 \\
\hline
\end{tabular}

A Figura 4 apresenta o modelo teórico de semivariograma que se ajustou melhor para combinação das duas direções

Tabela 1. Variáveis físicas medidas no reservatório de Nova Avanhandava em 12/12/2011 

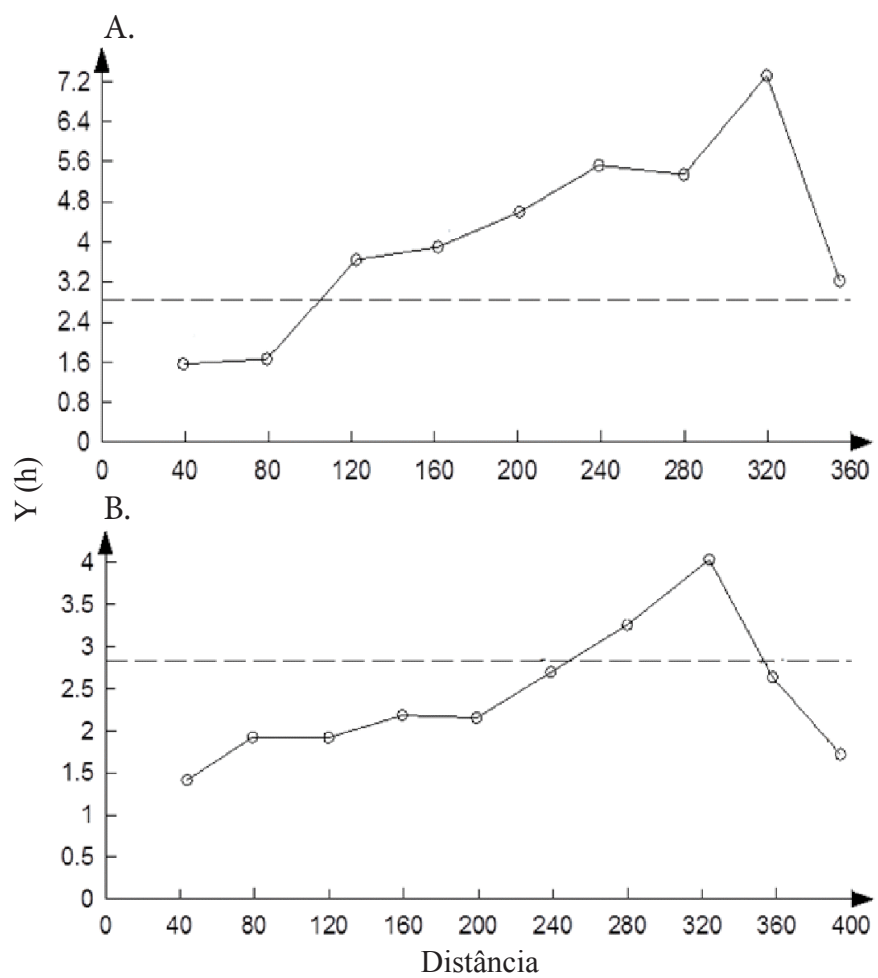

Figura 3. Semivariogramas nas direções de $45^{\circ}(\mathrm{A})$ e $135^{\circ}(\mathrm{B})$

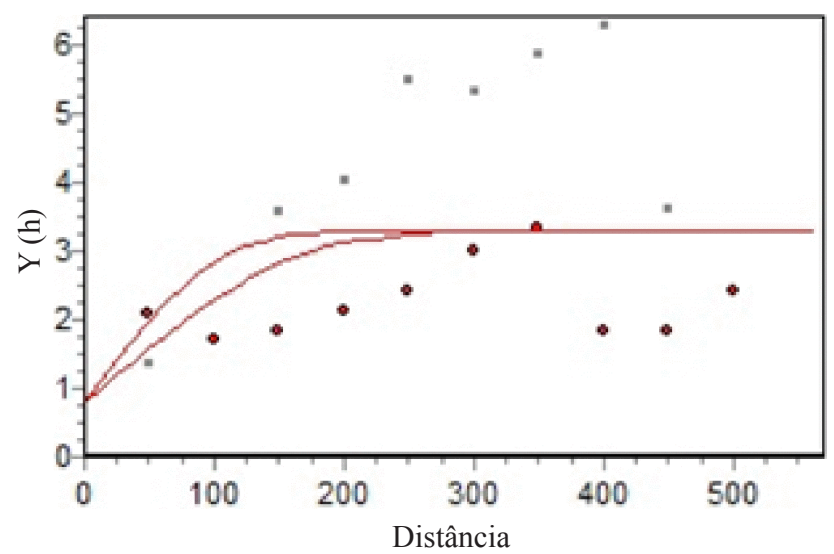

Figura 4. Modelo resultante da combinação das direções de $135^{\circ}$ e $45^{\circ}$

anteriormente citadas. Foi utilizado o modelo esférico nas duas direções $\left(135^{\circ}\right.$ e $\left.45^{\circ}\right)$ com valor de efeito pepita para os dois semivariogramas igual a 0,80 .

Nota-se que a direção de $45^{\circ}$ possui patamar em 3,8 e alcance de $200 \mathrm{~m}$ e a direção de $135^{\circ}$ possui patamar em 2,8 e alcance de $325 \mathrm{~m}$. Obteve-se o valor de 0,61 referente à razão de anisotropia, através da divisão dos alcances nas direções de menor e maior continuidade, respectivamente. O modelo resultante aplicado na inferência espacial da concentração de ficocianina na área de estudos, é expresso pela Eq. 2:

$$
0.800000 \mathrm{Nug}(0)+1 \mathrm{Sph}(325,135,0.61)+1.5 \mathrm{Sph}(200,45,0.61)
$$

Após efetuar a modelagem do semivariograma cruzado, fez-se a interpolação dos dados de ficocianina por meio da krigagem ordinária utilizando-se uma máscara com resolução de $5 \mathrm{~m}$ e raio de interpolação de $70 \mathrm{~m}$. A distribuição espacial da concentração de ficocianina na área de estudos é mostrada na Figura 5.

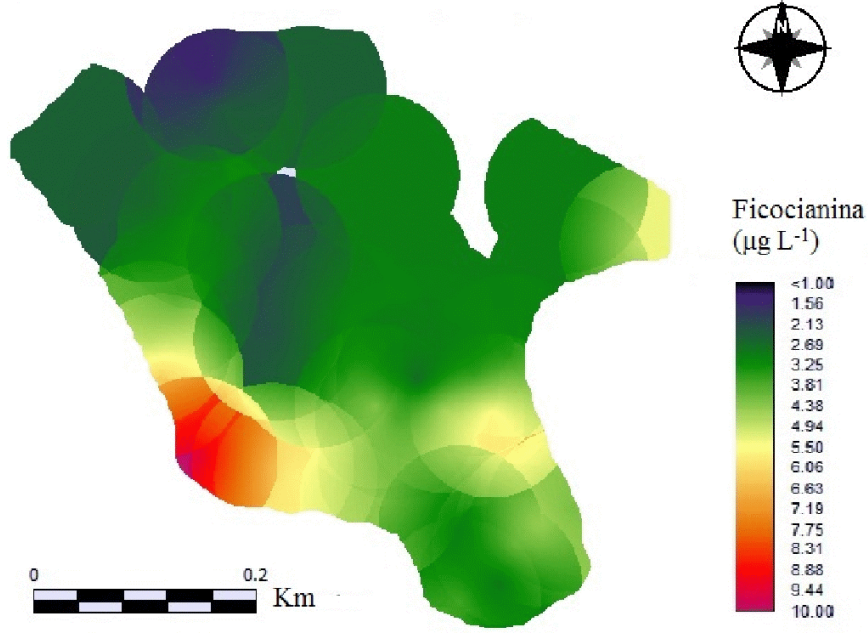

Figura 5. Inferência espacial da concentração de ficocianina na área de estudos, obtida por krigagem ordinária

As maiores concentrações de ficocianina estão localizadas nas margens do reservatório, especificamente nos locais em que os pontos de amostragem foram adensados. Construiu-se, a fim de verificar a confiabilidade dos valores interpolados, o mapa de variância do erro de estimação para a variável concentração de ficocianina, o qual é mostrado na Figura 6.

A variância da krigagem é obtida em função do estimador e da distribuição espacial das amostras, não se considerando o valor do atributo; assim, nos locais nos quais os valores interpolados coincidem com os pontos amostrais, a variância é zero e aumenta com sua distância. Na Figura 6 as menores variâncias estão representadas nos tons de azul-escuro e as maiores em tons avermelhados, as quais ocorrem na parte superior do mapa, cuja amostragem é menos densa, resultando em menor precisão da inferência; apesar disto, o erro médio quadrático (EMQ) obtido no processo de inferência espacial da ficocianina por krigagem ordinária, foi de 0,98 , mostrandose satisfatório.

Por fim, realizou-se a divisão dos valores de concentrações em cinco intervalos de $2 \mu \mathrm{g} \mathrm{L}^{-1}$. A Figura 7 apresenta o mapa temático resultante do fatiamento em cinco classes da imagem gerada pela interpolação por krigagem ordinária.

O mapa temático indicando distribuição das concentrações de ficocianina em intervalos de valores de $2 \mu \mathrm{g} \mathrm{L}^{-1}$ reforça a condição de pequena atividade de cianobactérias na área

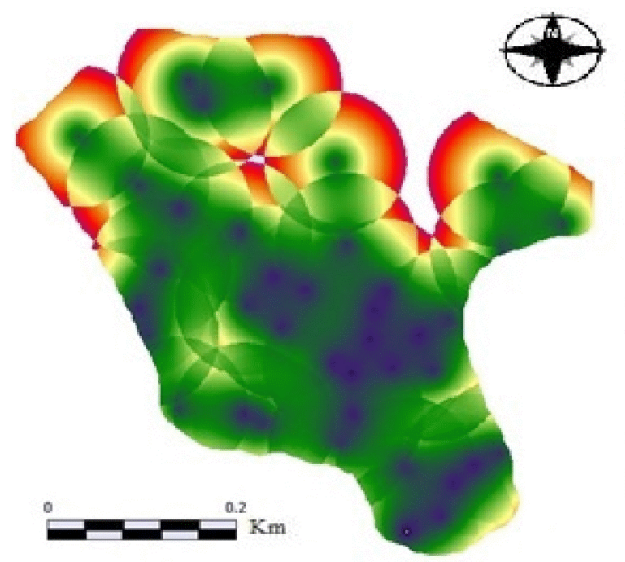

Variância do erro $\left(\mu \mathrm{L}^{-1}\right)$

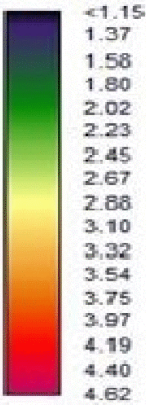

Figura 6. Distribuição espacial da variância do erro de estimação da concentração de ficocianina 


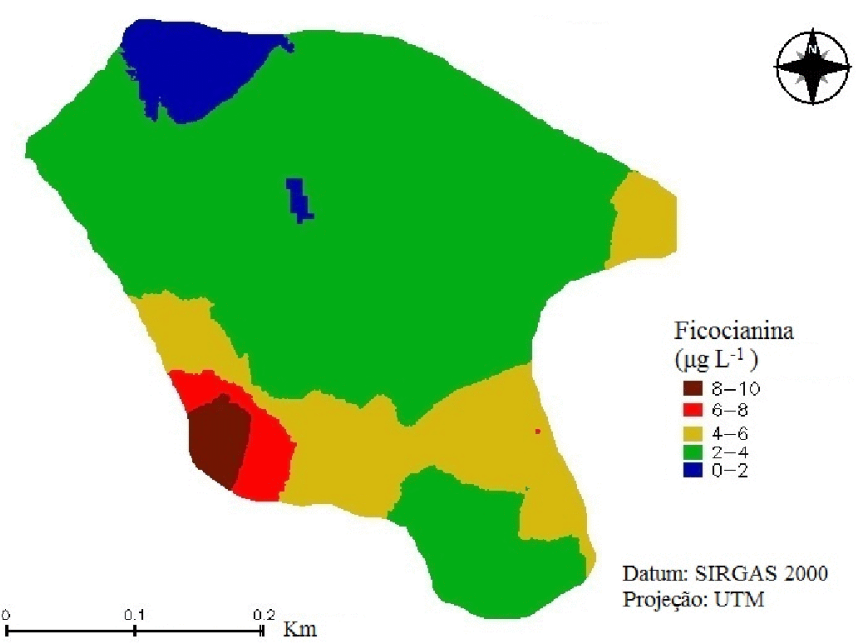

Figura 7. Mapa temático resultante do fatiamento dos valores de concentração de ficocianina

de estudo e do potencial da fluorimetria in vivo na detecção dessas pequenas concentrações. Por outro lado, a inferência geoestatística permitiu representar a distribuição espacial da ocorrência de cianobactérias e acessar o erro da estimativa, o que é um diferencial quando se trata da inferência geográfica. Trabalhos encontrados na literatura especializada se referem à utilização do pigmento ficocianina como indicador da densidade de cianobactérias, apesar de muitas instituições, como o Ministério de Saúde (Brasil, 2011) recomendarem a contagem de células e a análise da concentração de clorofila-a como os parâmetros utilizados como alerta de risco de cianobactérias em mananciais.

Randolph et al. (2008) constataram, em seus estudos, que a correlação entre a concentração de clorofila-a e o biovolume de cianobactérias era baixa $(r=0,66)$. Por outro lado, os referidos autores observaram uma forte correlação $(\mathrm{r}=0,87)$ entre a concentração de ficocianina e o biovolume de cianobactérias. Consoante com tais resultados, Bastien et al. (2011) observaram alto coeficiente de correlação ( $\mathrm{r}=$ 0,83 ) entre a fluorescência da ficocianina e o biovolume de cianobactérias; entretanto, nenhuma relação foi encontrada entre a fluorescência ou biovolume de cianobactérias com as cianotoxinas $(r=0,22)$.

Brient et al. (2008) afirmam que a quantidade de ficocianina é proporcional ao volume da célula, bem como ao grupo ao qual pertence. Os autores citados utilizaram o flurômetro TRIOS micro Flu-blue para monitoramento da água no oeste da França e observaram que o coeficiente de determinação entre a concentração de clorofila-a e o número de células de cianobactérias, foi baixo $\left(\mathrm{R}^{2}=0,42\right)$. Os resultados foram, porém, satisfatórios quando se relacionou a fluorescência da ficocianina com o biovolume de cianobactérias $\left(R^{2}=0,78\right)$ ou com o número de células de cianobactérias $\left(\mathrm{R}^{2}=0,74\right)$.

Os resultados encontrados no presente trabalho também apresentaram resultados satisfatórios para o coeficiente de determinação entre a concentração de ficocianina e os dados estimados pelo modelo $\left(R^{2}=0,81\right)$. Entretanto, quando foram relacionados os dados de concentração da clorofila-a e a concentração de ficocianina foi observado um coeficiente de determinação baixo $\left(R^{2}=0,40\right)$. Tais resultados evidenciam a vantagem do uso da ficocianina como alerta da presença de cianobactérias mas, conforme destacado por Seppala et al. (2007), o método de fluorescência in vivo do fitoplâncton não deve ser considerado uma forma alternativa para identificação e quantificação microscópica e sim um complemento aos demais métodos tradicionais.

\section{Conclusões}

1. O método da fluorescência in vivo para a detecção de cianobactérias mostrou-se viável, ainda que a medição in situ seja realizada em condições de baixa concentração de ficocianina.

2. A krigagem ordinária se mostrou um interpolador eficiente, pois além de possibilitar a definição da forma e domínio a ser considerada na interpolação, permite modelar a incerteza associada à inferência, por meio do mapa de variância do erro.

3. A detecção de ficocianina pelo método da fluorescência in vivo se apresenta como ferramenta complementar rápida e eficiente no monitoramento de cianobactérias.

\section{Agradecimentos}

À Coordenação de Aperfeiçoamento de Pessoal de Nível Superior - CAPES, pela bolsa de estudos, e à Fundação de Estudos e Pesquisas Agrícolas e Florestais - FEPAF.

\section{Literatura Citada}

Agha, R.; Cirés, S.; Wormer, L.; Dominguez, J. A.; Quesada, A. Multiscale strategies for the monitoring of freshwater cyanobacteria: reducing the sources of uncertainty. Water Research, v.46, p.30433053, 2012. http://dx.doi.org/10.1016/j.watres.2012.03.005

Bastien, C.; Cardin, R.; Veilleux, E.; Deblois, C.; Warren, A.; Laurion, I. Performance evaluation of phycocyanin probes for the monitoring of Cyanobacteria. Journal of Environmental Monitoring, v.13, p.110-118, 2011. http://dx.doi.org/10.1039/c0em00366b

Brasil. Ministério da Saúde. Portaria no 2.914. Dispõe sobre os procedimentos de controle e de vigilância da qualidade da água para consumo humano e seu padrão de potabilidade. Diário Oficial da União, Brasília, 12 Dez. 2011.

Brient, L.; Lengronne, M.; Bertrand, E.; Rolland, D.; Sipel, A.; Steinmann, D.; Baudin, I.; Legeas, M.; Rouzic, B. Le; Bormans, M. A phycocyanin probe as a tool for monitoring cyanobacteria in freshwater bodies. Journal of Environmental Monitoring, v.10, p.248-255, 2008. http://dx.doi.org/10.1039/b714238b

Calijuri, M. C.; Alves, M. S. A. A.; Santos, A. C. A. Cianobactérias e cianotoxinas em águas continentais. São Carlos: RiMa, 2006. 118p.

FUNASA - Fundação Nacional de Saúde. Cianobactérias tóxicas na água para consumo humano na saúde pública e processos de remoção em água para consumo humano. Brasília: Ministério da Saúde: Fundação Nacional de Saúde, 2003. 56p.

Goterman, H. L. Methods for physical and analysis of fresh waters. Limnological Institute. Oxford: Blackwell Scientific. 2.ed. 1978. $213 p$.

Gregor, J.; Marsalek, B.; Sipkova, H. Detection and estimation of potentially toxic cyanobacteria in raw water at the drinking water treatment plant by in vivo fluorescence method. Water Research, v.41, p.228-234, 2007. http://dx.doi.org/10.1016/j. watres.2006.08.011 
Izydorczyk, K.; Tarczynska, M.; Jurczak, T.; Mrowczynski, J.; Zalewski, M. Measurement of Phycocyanin Fluorescence as an online early warning system for cyanobacteria in reservoir intake water. Environmental Toxicology, v.4, p.425-430, 2005.

Landim, P. M. B. Análise estatística de dados geológicos. São Paulo: UNESP, 1998. 226p.

Randolph, K.; Wilson, J.; Tedesco, L.; Li, L.; Pascual, D. L.; Soyeux, E. Hyperspectral remote sensing of cianobacteria in turbid productive water using optically active pigments chlorophyll a and phycocyanin. Remote Sensing of Environment, v.112, p-4009-4019, 2008.
Seppala, J.; Ylöstalo, P.; Kaitala, S.; Hällfors, S.; Raateoja, M.; Maunula, P. Ship-of-opportunity based phycocyanin fluorescence monitoring of the filamentous cyanobacteria bloom dynamics in the Baltic Sea. Estuarine, Coastal and Shelf Science, v.73, p.489-500, 2007. http://dx.doi.org/10.1016/j. ecss.2007.02.015

Song, K.; Li, L.; Tedesco, L.; Clercin, N.; Hall, B; Li, S.; Shi, K.; Liu, D.; Sun, Y. Remote estimation of phycocyanin (PC) for inland waters coupled with YSI PC fluorescence probe. Environmental Science and Pollution Research, v.20, p.5330-5340, 2013. http:// dx.doi.org/10.1007/s11356-013-1527-y 